\title{
Follow-up survey of anesthesiologists attending a trauma course in Spain
}

Authors: Duque P (1), Varela J.A (1), Terradillos E (1), Piñeiro P (1), Turegano F (2), Perez Diaz D (2). Institute: (1) Gregorio Marañon General Hospital, Dept of Anaesthesiology \& Intensive Care, Madrid, Spain, (2) Gregorio Marañon General Hospital, Dept of Surgery, Madrid, Spain.

\section{Background and Goal of Study}

The first three editions (2014-2016) of the DATC (Definitive Anesthetic Trauma Care) course were offered along with the surgical version, the Definitive Surgical Trauma Care (DSTC) course, in a combined programme on trauma care adapted for surgeons and anaesthesiologists. It covers technical knowledge and non-technical skills on trauma patient management.

The course has been highly evaluated each year, making it a good option in trauma training, following initial management principles based on European Society of Anesthesiology ETC course (European Trauma Course). Nowadays DATC course is already established in some european countries like Denmark, Holland, Norway, France and Portugal.

This trauma management course is intended to provide all target groups with an acceptable method of safe management, knowledge and skills, necessary to take care of the critical injured trauma patient. Little is known about the effects of such course on professional development. The aim of the study was firstly to assess the impact of the course on self-efficacy and daily clinical practice and, secondly on team work efficacy between anesthesiology and surgery during trauma management, by using a selfreported follow- up questionnaire.

\begin{tabular}{l|l|l|}
\hline DSTC course. & Combined DATC/DSTC. & Anesthetic collaboration in DSTC \\
\hline Germany & Netherlands & Sweden \\
\hline Austria & Denmark & Finland \\
\hline Italy & France & Norway \\
\hline Greece & Portugal & \\
\hline Israel & Spain & \\
\hline Cyprus & & \\
\hline Switzerland & & \\
\hline
\end{tabular}

\section{Materials and methods}

In these three editions (2014-2016), 100\% of the participants were senior anaesthesiologists $(n=36)$ and surgeons $(n=54)$ coming from all over Spain. Participants were asked to fill in anonymously a follow-up questionnaire sent by email. We obtain 15 responders $(41 \%)$ among anesthesiologists and 18 responders (33\%) between surgeons.

\section{Results and discussion}

Between anesthesiologist, regarding self-efficacy in trauma care: $90 \%$ of the responders considered the course quite or very beneficial for their clinical practice. $70 \%$ of participants reported an improvement on their ability to deal with major trauma in a high or very high degree after the course. $80 \%$ think the course can help anesthesiologist to improve knowledge in trauma care and would recommend it to a colleague. Subjective opinion about the role of the surgeons in trauma care has improved in $90 \%$.

Among surgeons, $90 \%$ of them considered the course quite or very beneficial for their clinical practice. $80 \%$ of participants reported an improvement on their ability to deal with major trauma in a high or very high degree after the course. $100 \%$ of the responders would recommend the course to another surgeon. $70 \%$ of the surgeons think DATC/DSTC course could very useful for improving relationships with the anesthesiologists.

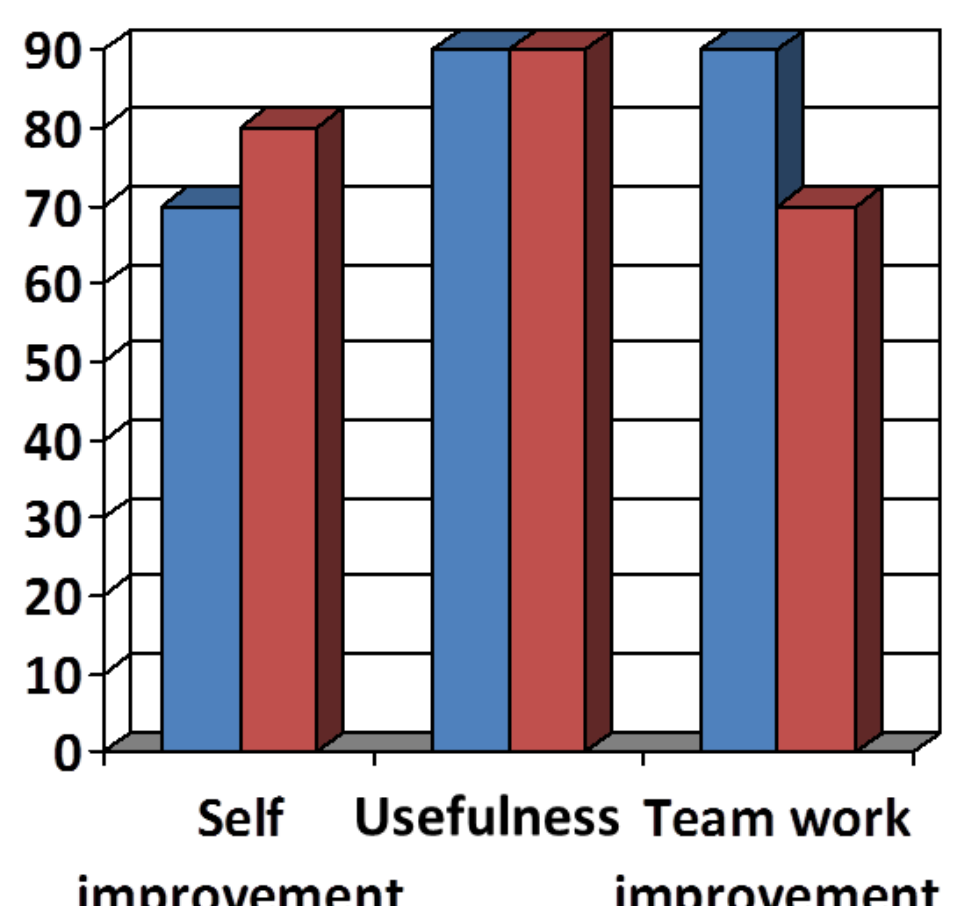

$\square$ Anesthesia $\square$ Surgery

\section{Conclusions}

Follow-up data from DATC and DSTC participants suggest a long term effect on self-efficacy and team work improvement in trauma care. Technical knowledge and non-technical skills practiced together between anesthesiologists and general surgeons may be beneficial in daily clinical practice and personal relationships.

\section{References}

1.- www.iatsic.org.

2.-www.aecirujanos.es. (Spanish).

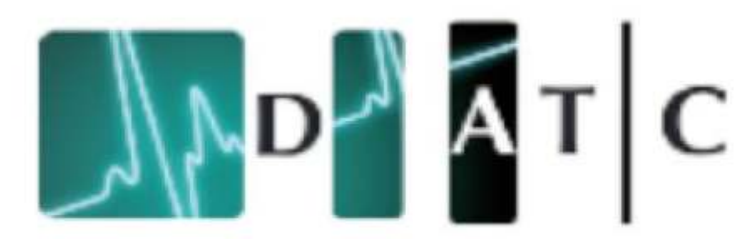

